ISSN 0001-6002/2010/52/3/148-153 Acta Médica Costarricense, (C)2010 Colegio de Médicos y Cirujanos
Cardiology Department, San Juan de Dios Hospital, Caja Costarricense del Seguro Social (Social Security Institution)

Abbreviations: CAD, coronary artery disease; myocardial perfusion imaging with SESTAMIBI, MPI-SESTAMIBI; HRmax, maximum cardiac frequency; HSJD, San Juan de Dios Hospital; DM, diabetes mellitus; AHT, arterial hypertension; CLOBI, Local Bioethics Committee; SD, standard deviation; ADA, anterior descending artery; RCA, right coronary artery; CXA, circumflex Artery.

Contact information:

Juan Pablo Solís Barquero

E-mail:_jpsolis@costarricense.cr, jpsolis@ihcai.org

PO Box201-2050, San Pedro

\section{Sensitivity and Specificity of Treadmill Test and Myocardial Perfusion Imaging with SESTAMIBI in the detection of Coronary Artery Disease at the Hospital San Juan de Dios}

Juan Pablo Solís-Barquero, Jaime Tortós-Guzmán

\begin{abstract}
Aim: Coronary artery disease is the first cause of mortality in the world and Costa Rica does not escape this reality. The treadmill test, myocardial perfusion imaging with SESTAMIBI and coronary angiography are methods used to diagnose this disease. Our country does not have data regarding the information provided by these tests. The research's aim is to determine the diagnostic performance of each of them.
\end{abstract}

Methods: It is an observational, analytic cohort research. Patients included were those with cardiovascular risk factors that had undergone a treadmill test, a myocardial perfusion imaging test and a coronary angiography at the San Juan de Dios Hospital, from 2003 to 2007 . The sensitivity and specificity of these tests was calculated. Also, a descriptive statistical analysis of the sample's characteristics and of the different cardiovascular risk factors was conducted.

Results: Eighty three patients were included in the study; $75 \%$ male. The main risk factors found were dyslipidemia $(84 \%)$ and artery hypertension $(70 \%)$. The treadmill test had a sensitivity of $40 \%$ and specificity of $57 \%$. Myocardial perfusion imaging with SESTAMIBI had a sensitivity of $66 \%$ and specificity of $71 \%$. The majority of patients had lesions in 1 or 2 coronary vessels, with more than $90 \%$ obstruction, mostly in the anterior descending artery.

Conclusion: A high prevalence of conventional risk factors was present in the studied population. The treadmill test showed a low sensitivity and specificity, however, it coincides with the range described by literature. The myocardial perfusion imaging with SESTAMIBI showed a significantly higher diagnostic performance $(p=0.05)$.

Key words: coronary artery disease, treadmill test, myocardial perfusion imaging, Technetium Tc 99m SESTAMIBI, coronary angiography.

Received: 14 August 2009 
An obstructive coronary artery disease (CAD) is defined by the presence of atherosclerotic lesions in one or more of the main branches of the epicardial coronary arteries, with obstructions greater than $50 \%$. It is known that over $90 \%$ of ischemic heart disease is due to CAD. ${ }^{1-3}$

According to data from the National Center for Health Statistics and the American Heart Association, heart disease affects over 71 million Americans and causes more than $30 \%$ of deaths in the United States. ${ }^{4,5}$ In Costa Rica, epidemiological data reports diseases of cardiovascular origin as the first cause of mortality, with a rate for 2006 , of 11/10 000 inhabitants. $^{6}$

CAD probability estimates should focus on the presence of risk factors. ${ }^{3}$ There are some scales, like Framingham's, to determine a patient's individual risk of having a major coronary event or death, in the next 10 years. ${ }^{7}$

The country has CAD diagnosis and assessment methods, among them the treadmill test, the myocardial perfusion imaging with SESTAMIBI (MPI-SESTAMIBI), with physical or pharmacological effort, and the coronary angiography ${ }^{8-10}$ The treadmill test has a highly inconsistent sensitivity and specificity that depends on the patient's sex, age and number of obstructed coronary vessels, maximum heart rate (HRmax) achieved during the test period, the probability of $\mathrm{CAD}$ and the experience of the health professional that performs the test. ${ }^{3}$ The MPI-SESTAMIBI is a nuclear medicine test performed in 2 stages: rest and exercise, and is able to differentiate if reperfusion defects are due to a former ischemic necrosis ("scarring") or to current myocardial ischemia. ${ }^{11}$ This test is also prescribed for risk stratification in emergency rooms, where it has been useful to improve the categorization between high and low risk patients. ${ }^{12}$ Coronary angiography is used for definite diagnosis of CAD and is still considered the "gold standard." ${ }^{3,9,13}$

Due to a lack of prediction data on these tests, the diagnostic performance (sensitivity, specificity) of treadmill testing and MPI-SESTAMIBI, compared with angiography was analyzed. Also, cardiovascular risk factors of the research's population were characterized.

\section{Methods}

The present is an observational, analytic cohort research. The studied population was adults, older than 18 years, from the area of attraction of the San Juan de Dios Hospital (HSJD) in San José, Costa Rica, with cardiovascular risk factors and suspected of or with CAD, which had undergone a treadmill test, a MPI-SESTAMIBI and a coronary angiography at this medical center, during the period from 1 January 2003 to 31 December 2007.
The primary source of information was the paper or microfilmed medical records in HSJD's archive. A special spreadsheet was designed to collect data. Each patient was identified with a consecutive number and their ID number. Information of the following variables was collected: age, sex and presence of the following cardiovascular risk factors: diabetes mellitus (DM), arterial hypertension (AHT), cigarette smoking, sedentary lifestyle, obesity, dyslipidemia and family history of heart disease; in addition, blood pressure values, lipids profile and the reason for requesting the tests. Finally, the treadmill test report was taken as: positive (due to ischemia or scarring), negative or undetermined, with the HRmax; the MPI-SESTAMIBI report as: positive (due to ischemia or scarring) or negative; and the coronary angiography as: CAD positive or negative, with the number of obstructed epicardial vessels and the percentage of obstruction.

The data was analyzed using the SPSS version 8.0 statistical package. Two by two tables were made to calculate the sensitivity and specificity of the treadmill test and MPI-SESTAMIBI, also running a logistic regression to determine statistical significance. Besides, a descriptive statistical analysis was carried out measuring position (mode, median) and dispersion measures (standard deviation, minimum and maximum values) for each one of the risk factor variables.

Research was conducted according to the principles of autonomy, justice, beneficence and non-maleficence and was approved by the HSJD Local Bioethics Committee (CLOBI), under document number CLOBIHSJD-038-2008.

\section{Results}

Out of 2967 angiograms performed in HSJD, 1347 were excluded, because they corresponded to studies in other territories (brain, carotid vessels, lung, aorta, iliac vessels and lower extremities). The remaining 1620 were coronary angiograms. The sample's size, with a confidence level of 0.95 , a variance of 0.2 and a maximum error of 0.05 was 214 patients; with a population adjustment. According to random tables, 304 medical records were selected and reviewed, in order to have a margin of 90 more patients. Although this number of medical records was reviewed, 221 did not meet all the research's inclusion criteria and the final sample was 83 patients, who concur with $25 \%$ of the medical records reviewed. (Figure 1) 
Of the patients included in the study, $62(75 \%)$ were male and $21(25 \%)$ female. The participant's mean age was 61 years, with a mode at 58 years; the minimum age was 35 years and maximum 85 .

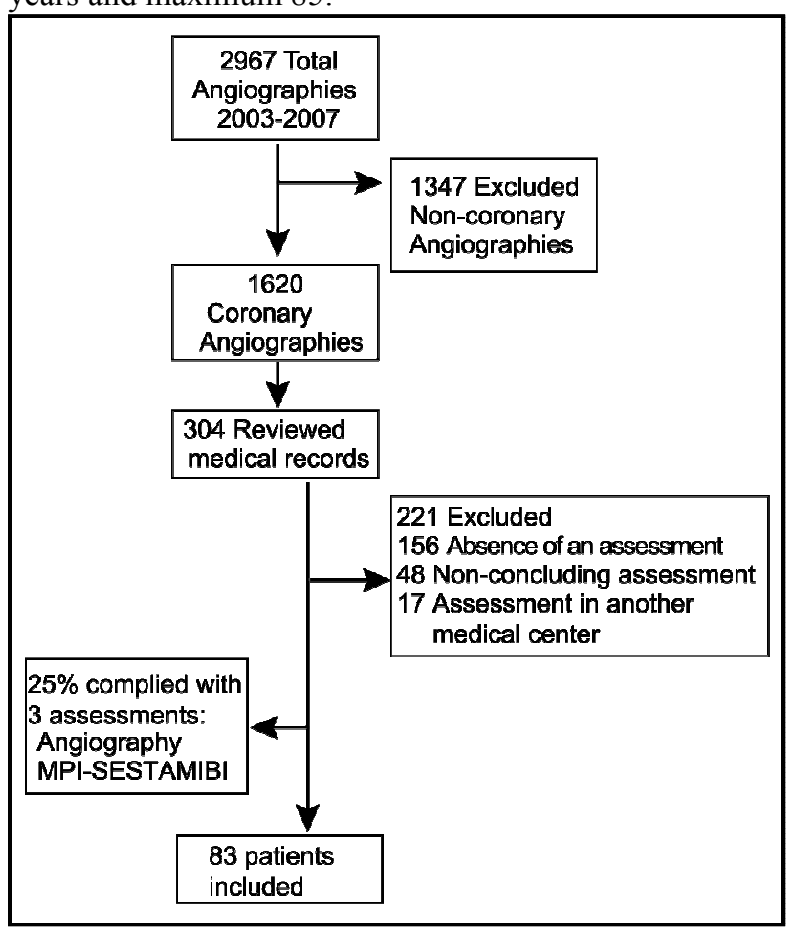

Figure 1. Sample selection process.

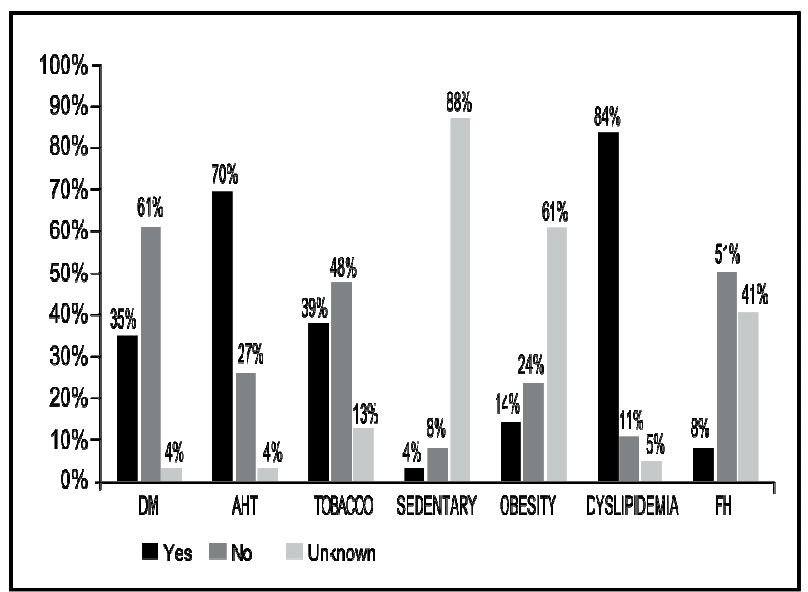

Figure 2. Risk factors in the studied sample. 2003-2007.

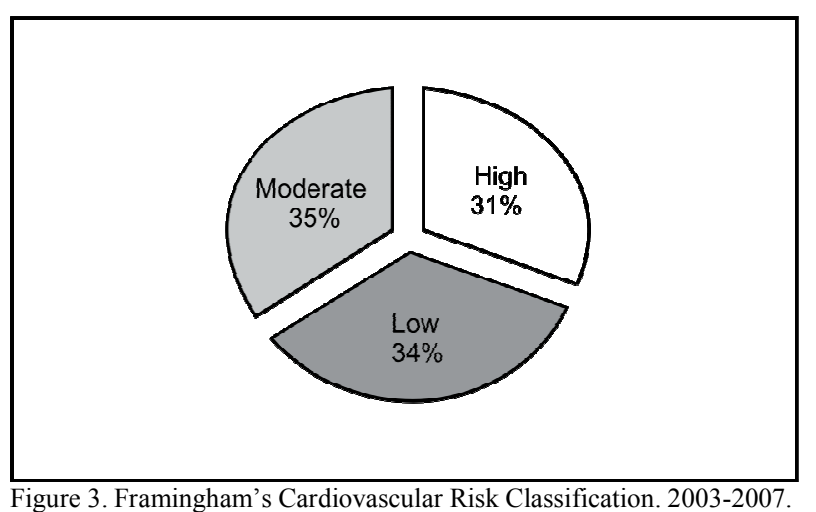

The risk factors found in the study, apart from gender and age over 65, were: DM, AHT, cigarette smoking, sedentary lifestyle, obesity, dyslipidemia and family history of heart disease. As shown in Figure 2, the main risk factors for this population were dyslipidemia, in $84 \%$ of cases, and AHT, in $70 \%$ of cases, with a frequency of DM of $35 \%$ and cigarette smoking of $39 \%$. The frequency for a sedentary lifestyle was unknown in $88 \%$ of the cases, of obesity in $61.5 \%$ and of family history in $41 \%$.

Other documented data included the presence of thrombophilias in 3 patients: 2 diagnosed of Antiphospholipid Syndrome and 1 with antithrombin deficiency. Besides, 45 patients had one or more coronary stents and 16 patients underwent a cardiac revascularization surgery.

According to Framingham's Classification, approximately one third of individuals were low-risk patients, another third moderate-risk and a last third, high-risk patients. (Figure 3)

With regard to the lipid profile, 79 patients had at least one report in their medical record and 4 patients did not have. From the analyzed data for total cholesterol, the average was $189 \mathrm{mg} / \mathrm{dl}$, with a standard deviation (SD) of $44 \mathrm{mg} / \mathrm{dl}$, a minimum value of $92 \mathrm{mg} / \mathrm{dl}$ and a maximum one of $362 \mathrm{mg} / \mathrm{dl} ; 61 \%$ had levels below 200 $\mathrm{mg} / \mathrm{dl}$ and 34\% levels equal or higher than $200 \mathrm{mg} / \mathrm{dl}$. With respect to LDL, the mean was $111 \mathrm{mg} / \mathrm{dl}$, with a $\mathrm{SD}$ of $42 \mathrm{mg} / \mathrm{dl}$, a minimum value of $24 \mathrm{mg} / \mathrm{dl}$ and a maximum one of $331 \mathrm{mg} / \mathrm{dl} ; 39 \%$ had levels below 100 $\mathrm{mg} / \mathrm{dl}$ and $57 \%$, equal to or greater than $100 \mathrm{mg} / \mathrm{dl}$. HDL had an average of $38 \mathrm{mg} / \mathrm{dl}$, with a SD of 10 $\mathrm{mg} / \mathrm{dl}$. On average, triglycerides were of $242 \mathrm{mg} / \mathrm{dl}$, with a SD of $149 \mathrm{mg} / \mathrm{dl}$, a minimum level of $61 \mathrm{mg} / \mathrm{dl}$ and a maximum one of $726 \mathrm{mg} / \mathrm{dl}$. The reasons for studying these patients were: 33 patients with acute myocardial infarction, 18 with stable angina, 18 for unstable angina, 6 for heart surgery, 4 for atypical chest pain, 3 for arrhythmia and 1 to identify the cardiac reserve.

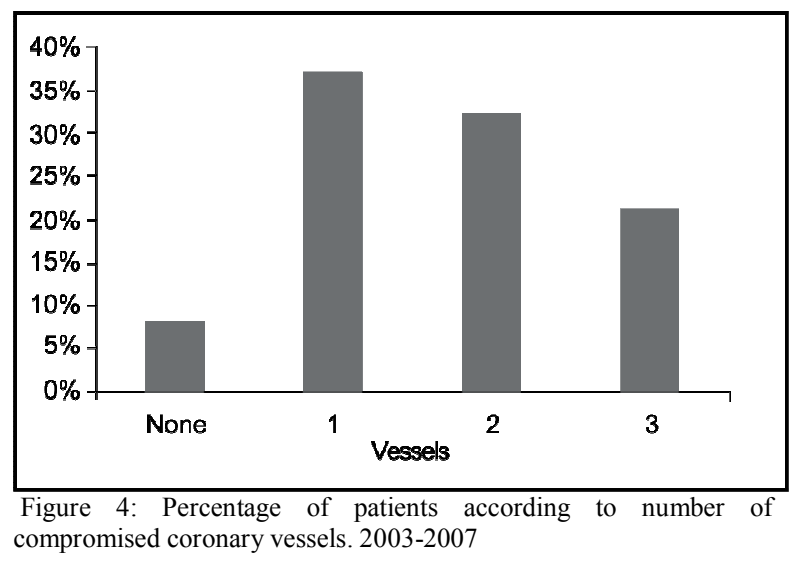




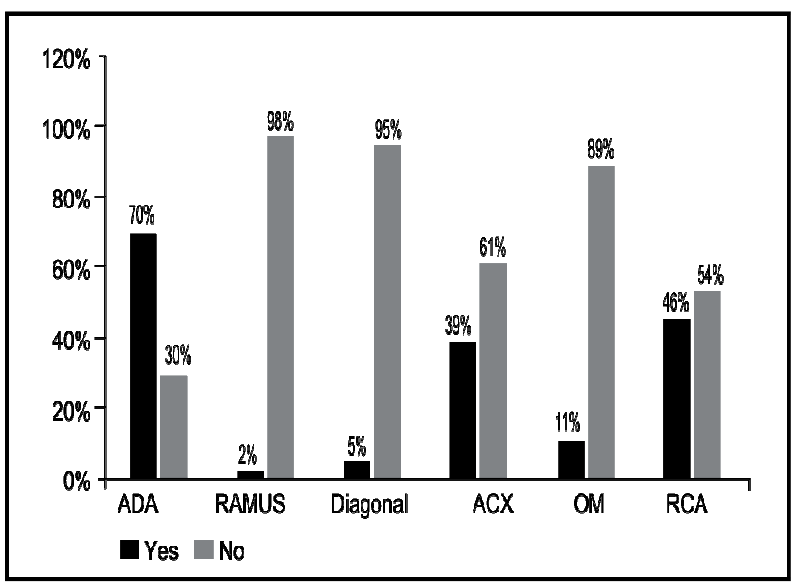

Figure 5: Percentage of lesions according to coronary vessels. 2003-2007

The treadmill test showed a $40 \%$ sensitivity and $57 \%$ specificity. The average HRmax was $88 \%$.

The MPI-SESTAMIBI showed a $66 \%$ sensitivity and $71 \%$ specificity. It revealed the presence of myocardial scarring in $46 \%$ of the cases, ischemia in $32.5 \%$ of the cases and mixed defects in $21.5 \%$ of the cases.

The logistic regression analysis determined significant differences between the MPI-SESTAMIBI and the treadmill test $(p=0.05)$.

According to the number of compromised vessels by the coronary angiography, it was seen that the majority of patients showed disease in one or two vessels, 33\% and $37 \%$, respectively. The other $22 \%$ had 3 affected vessels. (Figure 4)

According to the percentage of obstruction of the coronary vessel's lumen, there were 140 lesions: 14 with obstructions between 50 and 70 percent, 39 with obstructions between 70 and 90 percent and 87 with more than $90 \%$ obstructions.

Figure 5 shows the percentage of compromised coronary vessels. The left anterior descending artery (ADA), found in $70 \%$ of cases, was the most affected one in the research's sample, followed by the right coronary artery (RCA), found in $46 \%$ of cases, and by the circumflex artery (ACX), found in $39 \%$ of cases.

\section{Discussion}

The studied population had in average 61 years, which is within the range in which CAD occurs the most. ${ }^{6}$ Important cardiovascular risk factors were identified, especially dyslipidemia, AHT, and in one third of them, DM and cigarette smoking.
It is interesting to note that more than $50 \%$ failed to meet the goals of optimal treatment for their dyslipidemia; only $39 \%$ of the patients had LDL cholesterol below $100 \mathrm{mg} / \mathrm{dl}$. In the majority of medical records a sedentary lifestyle and obesity was not recorded, therefore leaving an open questions as to their role as risk factors, due to the high prevalence of high degree coronary obstructions in these patients.

The studied population behaved like patients under moderate and high-risk, since the majority of them had significant affections and in multiple coronary vessels.

The treadmill test showed a low sensitivity and specificity, however, it coincides with the range described in the bibliography. ${ }^{3,13}$ Many studies have shown, even in Detrano's meta-analysis, that with 24000 included patients, the sensibility ranges oscillate between 23 and 100 percent, with an average of $68 \%$ and specificity between 17 and 100 percent, with an average of $77 \% .^{14,15}$

The MPI-SESTAMIBI showed a higher diagnostic performance than the treadmill test, however with values below the ones reported by literature. In Gyongyosi's study, an 81-90\% sensitivity was reported and specificity between 74 and $98 \% .{ }^{16}$ This could be related to the sample's size.

Although the research was limited because of failure to achieve the ideal sample size, including only $25 \%$ of the medical records reviewed, the explanation was that many of the studies were not conducted at an appropriate time, sometimes due to damage or repair of medical equipment, or because of appointments programmed for several months ahead, so in the majority of the cases, the coronary angiography was the only practiced test.

This data is relevant, as it is the country's only information to diagnose the CAD, besides; there is no previously published data.

In conclusion, the main CAD risk factors in the patients studied are dyslipidemia and AHT. In addition, the MPI-SESTAMIBI has a significantly higher diagnosis performance $(p=0.05)$ than the treadmill test for the detection of this entity. And, finally, the majority of coronary injuries at the moment of diagnosis have obstructions superior to $90 \%$ of the vessel's lumen, being the ADA the most affected one.

The authors' recommendations are:

1. To improve medical history's of medical records, where conventional risk factors such as a sedentary lifestyle and obesity are included.

2. To make another comparative study, ideally a prospective one, with a larger sample. 


\section{Acknowledgements:}

To Viviana Solís Barquero, for all her support in the preparation of statistics and graphics for this article; to Monserrath Hernández Fernández, for reviewing format and text of the article.

\section{References}

1. Libby P, Bonow R, Zipes D and Mann D. Assessment of the physiology and pathophysiology of myocardial blood flow, myocardial metabolism, and ventricular function. En: Braunwald's Heart Disease. 8th edition, 2007: 345-92.

2. Salguero Boda R, Sánchez Pérez I, Matía Francés R y Sáenz de la Calzada Campos C. Cardiopatía isquémica. Concepto. Aspectos epidemiológicos. Etiopatogenia. Clasificación biológica y clínica. Implicaciones en la calidad de vida. Medicine 2005; 9: 2571-79.

3. Grech Ever D. ABC of interventional cardiology. Pathophysiology and investigation of coronary artery disease. BMJ 2003; 326: 102731 .

4. National Center for Health Statistics, Center for Disease Control and Prevention, US Department of Health and Human Services. Fast stats A to Z: leading causes of death. Accessed in January 2008. En: http://www.cdc.gov/nchs/fastats/lcod.htm

5. American Heart Association. Cardiovascular disease statistics. $\begin{array}{llll}\text { Accessed in } 2008 . & \end{array}$ http://www.americanheart.org/presenter.jhml

6. Situación de Salud de Costa Rica 2007. Ministerio de Salud y Organización Panamericana de Salud (OPS). Accessed in January 2008.En: http://www.estadonacion.or.cr/compendio/SOC salud96 00.htm

7. Wilson PW, D’Agostino R, Levy D, Belenger AM, Silbershatz H and Kannel WB. Prediction of coronary heart disease using risk factor categories. Circulation 1998; 97: 1837-47.

8. Selker P, Zalenski RJ, Antman EM, Aufderheite TP, Bernard SA, Bonow RD et al. An evaluation of technologies for identifying acute cardiac ischemia in the emergency department: a report from a National Heart Attack Alert Program Working Group. Ann Emerg Med 1997; 29: 13-87.

9. Sanjay KP, Ravi GA, and Dudley JP. Recent development in noninvasive cardiology. BMJ 2004; 329: 1386-89.

10. Kuo D, Dilsizian V, Presad R and White C. Emergency Cardiac Imaging: State of the Art. Cardiol Clin 2006; 24:53-65.

11. Mahenthiran J, Bangalore S, Yao S and Chaudhry F. Comparison of prognostic value of stress echocardiography versus stress electrocardiography in patients with suspected coronary artery disease. Am J Cardiol 2005; 96: 628-34.

12. Udelson J, Beshansky J and Ballin D. Myocardial Perfusion Imaging for Evaluation and Triage of Patient with Suspected Acute Cardiac Ischemia: A randomized controlled trial. JAMA 2002; 288: 229300 .

13. Junnila JL and Runkle GP. Coronary Artery Disease Screening, Treatment, and Follow-up. Prim Care Clin Office Pract 2006; 33: 863-85.

14. Tortós-Guzmán J. La prueba de esfuerzo en la práctica diaria Actual Med Period 2002; 11: 1-7.
15. Detrano R, Gianrossi R and Froelicher VF. The diagnostic accuracy of the exercise electrocardiogram: a meta-analysis of 22 years of research. Prog Cardiov Dis 1989; 32: 173-206.

16. Gyongyosi M, Maul F, Standke R, Kattenbach M and Hor G. Coronary artery stenosis and occlusion: value of 99Tcm-MIBI SPECT. Nucl Med Com 1994; 15: 593-603.

17. Mack MB, Ringqvist I, Fisher LD, Davis KB, Chaitman BR, Kouchoukos NT et al. Coronary Artery Surgery Study Group (CASS). A randomized trial of coronary artery bypass surgery. Survival data. Circulation 1983; 68: 939-50.

18. Gianrossi R, Detrano R, Mulvihill D, Lehmann K, Dubach P, Colombo A et al. Exercise-induced ST depression in the diagnosis of coronary artery disease: a meta-analysis. Circulation 1989; 80: 87-98.

19. Fleichmann KE, Hunink MG, Kuntz KM and Douglas PS. Exercise Echocardiography or Exercise SPECT Imaging? A Meta-analysis of Diagnostic Test Performance. JAMA 1998; 280: 913-20.

20. Gallager M, Ross M, Raff G, Goldstein J, O'Neill W and O'Neil B. The Diagnostic Accuracy of 64-Slice Computed Tomography Coronary Angiography Compared with Stress Nuclear Imaging in Emergency Department Low-Risk Chest Pain Patients. Ann Emerg Med 2007; 49: 125-36.

21. Beller GA and Kramer CM. Nuclear Medicine and Computed Tomography. En: Goldman et al. Cecil Medicine. EEUU. 23rd edition. Saunders, 2007: 235-76.

22. Weissman I, Dickinson C, Dworkin H, O'Neill W, Juni J. Costeffectiveness of myocardial perfusion imaging with SPECT in the emergency department evaluation of patients with unexplained chest pain. Radiology 1996; 199: 353-357.

23. Skiles JA. Nuclear Imaging. En: Griffin Brian P, and Topol Eric J. Manual of Cardiovascular Medicine. EEUU. 2nd edition. Lippincott Williams \& Wilkins, 2004: 578-90.

24. Ellestad MH. Pruebas de esfuerzo: bases y aplicación clínica. Barcelona, España. 3era edición. Ediciones Consulta, 1988: 1576.

25. González U and Fonseca C. Estudio SPECT de perfusión miocárdica con esfuerzo físico (Protocolo de 1 día). Normas del Servicio de Medicina Nuclear. Hospital San Juan de Dios. CCSS. -Unpublished-.

26. González U and Fonseca C. Estudio SPECT de perfusión miocárdica con esfuerzo farmacológico (Protocolo de 1 día). Normas del Servicio de Medicina Nuclear. Hospital San Juan de Dios. CCSS. -Unpublished-

27. Strauss HW, Miller D, Wittry M, Cerqueira M, García E, Iskandrian A et al. Guidelines for Myocardial Perfusion Imaging. Society of Nuclear Medicine Procedure Guidelines Manual 2008; 36: 155-161.

Translate by: Natalia Porras 